\title{
Phase and structural transformations in a nanocrystalline alloy $\mathrm{Fe}_{72.5} \mathrm{Cu}_{1} \mathrm{Nb}_{2} \mathrm{Mo}_{1.5} \mathrm{Si}_{14} \mathrm{~B}_{9}$
}

\author{
N. N. Nikul'chenkov ${ }^{\dagger, 1}$, A. S. Yurovskikh ${ }^{1}$, Y.N. Starodubtsev ${ }^{1,2}$, M. L. Lobanov ${ }^{1}$ \\ †nikolai.nikulchenkov@urfu.ru \\ ${ }^{1}$ Ural Federal University, 19 Mira St., Ekaterinburg, 620002, Russia \\ ${ }^{2}$ Research and Production Enterprise «Gammamet», 92 Tatishcheva St., Ekaterinburg, 620028, Russia
}

\begin{abstract}
The material for investigation was a ribbon with an amorphous structure obtained by the melt spinning technique from a melt of molybdenum-modified Finemet-type high-permeability $\mathrm{Fe}_{72.5} \mathrm{Cu}_{1} \mathrm{Nb}_{2} \mathrm{Mo}_{15} \mathrm{Si}_{14} \mathrm{~B}_{9}$ alloy. Using the methods of non-ambient $\mathrm{X}$-ray diffraction, calorimetry, and dilatometry, temperature intervals of transformations during the transition of material from the amorphous state to the nanocrystalline one with subsequent recrystallization were determined. Each method was characterized by its own heating rate: $1 \mathrm{~K} / \mathrm{min}$ for the non-ambient X-ray diffraction, $30 \mathrm{~K} / \mathrm{min}$ for calorimetry, and $20 \mathrm{~K} / \mathrm{min}$ for dilatometry. Regardless of the heating rate, phase and structure transformations (crystallization and recrystallization, respectively) were observed sequentially. With decreasing heating rate, the crystallization temperature significantly decreased and the recrystallization temperature slightly decreased. Specific heats of crystallization $(386 \mathrm{~kJ} / \mathrm{mol})$ and recrystallization $(88 \mathrm{~kJ} / \mathrm{mol})$ were calculated from calorimetry data. Basing on the results of X-ray diffraction and calorimetric studies, the possibility of using the structural unit model was analyzed to describe the amorphous state. It was supposed that any condensed state of the material (amorphous, nanocrystalline and recrystallized) were distinguished by different sizes of coherent scattering regions (CSRs). The lower estimate of coherent scattering regions size was made from the X-ray diffraction halo width for the amorphous state and (110) diffraction line broadening for polycrystals. The Wigner-Seitz cell (truncated octahedron) containing one atom has been adopted as a structural unit. Specific heats of transformations were compared to the values of energies related to the transitions of atoms from CSR borders to lattice sites. Satisfactory applicability of the structural unit model for the description of the amorphous state was demonstrated.
\end{abstract}

Keywords: amorphous state, high-permeability nanocrystalline alloy, nanocrystallization, non-ambient X-ray diffraction, structural unit model.

УДК: 53.087.3:543.423

\section{Фазовые и структурные превращения в нанокристаллическом сплаве $\mathrm{Fe}_{72.5} \mathrm{Cu}_{1} \mathrm{Nb}_{2} \mathrm{Mo}_{1.5} \mathrm{Si}_{14} \mathrm{~B}_{9}$}

Никульченков Н.Н. ${ }^{\dagger, 1}$, Юровских А. С. ${ }^{1}$, Стародубцев Ю.Н. ${ }^{1,2}$, Лобанов М. Л. ${ }^{1}$

†nikolai.nikulchenkov@urfu.ru

1Уральский федеральный университет имени первого Президента России Б. Н. Ельцина, ул. Мира, 19, 620002,

Екатеринбург, Россия

${ }^{2}$ Научно-производственное предприятие «Гаммамет», ул. Татищева, 92, офис 1, Екатеринбург, 620028, Россия

Материалом для исследования являлась металлическая лента с аморфной структурой, которая была получена методом быстрой закалки расплава из магнитомягкого сплава типа Finemet модифицированного молибденом $\mathrm{Fe}_{72.5} \mathrm{Cu}_{1} \mathrm{Nb}_{2} \mathrm{Mo}_{1.5} \mathrm{Si}_{14} \mathrm{~B}_{9}$. Методами терморентгеновского фазового, калориметрического и дилатометрического анализов определялись температурные интервалы превращений при переходе материала из аморфного состояния в нанокристаллическое с последующей рекристаллизацией. Каждый метод характеризовался собственной скоростью нагрева: рентгеновский - эффективная скорость нагрева 1 К/мин; калориметрический - $30 \mathrm{~K} /$ мин; дилатометрический - $20 \mathrm{~K} /$ мин. Независимо от скорости нагрева в материале последовательно наблюдались фазовое 
(кристаллизация) и структурное (рекристаллизация) превращения. С уменьшением скорости нагрева существенно понижается температура кристаллизации, а температура рекристаллизации снижается незначительно. Из калориметрических данных были рассчитаны удельные теплоты кристаллизации - 386 кДж/моль и рекристаллизации 88 кДж/моль.На основе сопоставления результатов рентгенографических и калориметрических исследований проанализирована возможность применения модели структурных единиц к описанию аморфного состояния. Предполагалось, что все конденсированные состояния материала (аморфное, нанокристаллическое и рекристаллизованное) отличаются размерами областей когерентного рассеяния (ОКР). Нижняя оценка размеров ОКР проводилась по ширине рентгеновского гало для аморфного состояния и уширению дифракционной линии (110) для поликристаллов. В качестве структурной единицы принималась ячейка Вигнера-Зейтца (усеченный октаэдр), включающая один атом. Сравнивались удельные теплоты превращений с количеством энергии, возникающей при переходе атома с границы ОКР в узел кристаллической решетки. Показана удовлетворительная применимость модели структурных единиц для описания аморфного состояния.

Ключевые слова: аморфное состояние, магнитомягкий нанокристаллический сплав, нанокристаллизация, терморентгеновский фазовый анализ, модель структурных единиц.

\section{1. Введение}

Начало изучению аморфных материалов было положено Полом Дювезом (Pol Duwez) в 1960 году [1]. До настоящего времени сохраняющийся и расширяющийся интерес исследователей к металлическим стеклам [2-4] связан с тем, что материал в аморфном состоянии может обладать заметно лучшими механическими, антикоррозионными или магнитными свойствами по сравнению с поликристаллом [5]. Магнитопроводы, выполненные из металлических аморфных и нанокристаллических материалов, с успехом используются при производстве различных трансформаторов в широкой области частот [6]. Стоит отметить важность перехода аморфного материала к нанокристаллическому состоянию посредством термической обработки. Нанокристаллическая структура в сплавах на основе железа обладает существенно лучшим сочетанием магнитных свойств по сравнению с аморфным состоянием: высокой магнитной проницаемостью $\mu$, низкой коэрцитивной силы $H_{C}$, повышенной индукцией $B_{S}[7-9]$.

До настоящего времени дискуссионным остается описание структуры аморфного состояния на атомном уровне [10,11]. В [12] отмечено, что главными, не до конца решенными научными проблемами являются описания структуры объемных металлических стекол. Представления об аморфном состоянии, основанные на наличии в материале ближнего порядка, заменяются на модели, в которых структура материала представляется как регулярная, упорядоченная на уровне атомов по типу кластеров или структурных единиц [13-15].

Целью работы является оценка возможности применения различных методов к анализу структуры нанокристаллического сплава $\mathrm{Fe}_{72.5} \mathrm{Cu}_{1} \mathrm{Nb}_{2} \mathrm{Mo}_{1.5} \mathrm{Si}_{14} \mathrm{~B}_{9}$ на разных стадиях термической обработки.

\section{2. Материалы и методика исследований}

Объектом исследования являлся промышленный магнитомягкий сплав $\mathrm{Fe}_{72.5} \mathrm{Cu}_{1} \mathrm{Nb}_{2} \mathrm{Mo}_{1.5} \mathrm{Si}_{14} \mathrm{~B}_{9} \quad[6,16]$. Исходный образец представлял ленту толщиной 20 мкм и шириной 10 мм с аморфной структурой (аморфный прекурсор), которая изготовлялась методом быстрой закалки расплава на вращающийся барабан-холодильник.
Исследования проводили при нагреве аморфного прекурсора до температуры $700^{\circ} \mathrm{C}$. Для терморентгеновского фазового анализа (ТРФА) использовали установку Bruker ASX ADVANCE D8 с термокамерой AntonPaar HTK $1200 \mathrm{~N}$ в излучении $\mathrm{K}_{\alpha}$-Сo $\left(\lambda=1.79 \cdot 10^{-10}\right.$ м). Был получен набор дифрактограмм, снятых в интервале температур $100-700^{\circ} \mathrm{C}$ с шагом нагрева $25^{\circ} \mathrm{C}$. Каждая дифрактограмма снималась в изотермических условиях для диапазона углов $2 \theta=35-80^{\circ}$, в течение 25 минут. Скорость нагрева между съемками $30^{\circ}$ мин. Эффективная скорость нагрева образца составила 1\%

Нижняя оценка размеров областей когерентного рассеяния (L) производилась по уширению линии ОЦК-железа $\{110\}$ а и по гало для аморфного состояния с использованием формулы Шеррера [17]

$$
L_{x}=(K \cdot \lambda) /(\beta \cdot \cos \theta),
$$

где $K=$ const $\approx 0.9 ; \beta-$ интегральная ширина, выраженная в радианах; $\cos (\theta)-$ косинус угла $\theta$, который соответствовал положению центра тяжести дифракционной линии.

Согласно уравнению Вульфа-Брегга для материала в кристаллическом состоянии рассчитывалось межплоскостное расстояние $(d)$ по линии $\{110\}$. Для аморфного состояния по положению центра тяжести гало определялось среднее межатомное расстояние по первой координационной сфере.

Дилатометрический анализ проводили на установке Linseis L78 R.I.T.A. Были получены данные об изменении длины образца в процессе нагрева со скоростью $20 \mathrm{~K} /$ мин.

Калориметрический анализ проводили на установке Netzsch STA 449 C Jupiter со скоростью нагрева 30 К/мин. Тепловые эффекты рассчитывали методами численного интегрирования.

\section{3. Результаты и обсуждение}

Терморентгеновский анализ показал (Рис. 1), что при температуре $450^{\circ} \mathrm{C}$ на дифрактограмме фиксировалось перераспределение интенсивности рентгеновского излучения: гало заменялось на набор отдельных рефлексов $\{110\},\{200\}$, соответствующих ОЦК-решетке. Это однозначно указывает на начало процесса кристаллизации в образце. 


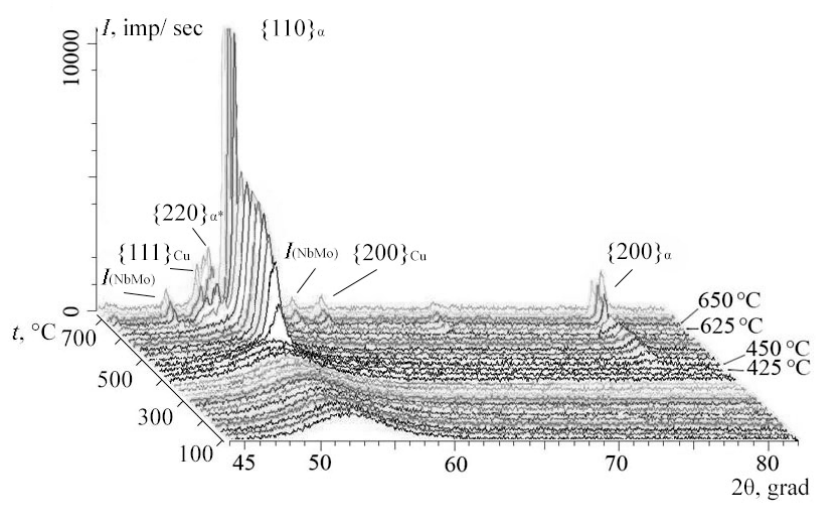

a

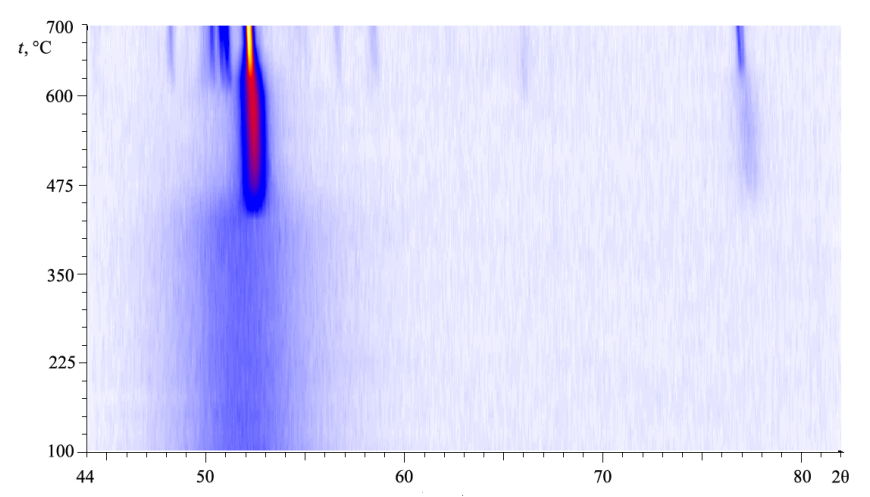

b

Pис. 1. (Color online) Набор дифрактограмм сплава $\mathrm{Fe}_{72.5} \mathrm{Cu}_{1} \mathrm{Nb}_{2} \mathrm{Mo}_{1.5} \mathrm{Si}_{14} \mathrm{~B}_{9}$, полученныхпри нагреве; в видедискретного набора (a); в виде непрерывного изменения интенсивности (b).

Fig. 1. (Color online) $\mathrm{Fe}_{72.5} \mathrm{Cu}_{1} \mathrm{Nb}_{2} \mathrm{Mo}_{1.5} \mathrm{Si}_{14} \mathrm{~B}_{9}$ alloy diffraction patterns set, received at heating; diffraction pattern as a discrete set (a); diffraction pattern as continuous intensity (b).

На дифрактограмме, полученной при температуре $650^{\circ} \mathrm{C}$ зафиксировано резкое изменение формы пиков, соответствующих твердому раствору на основе железа с ОЦК-решеткой: повышение их высоты приблизительно в два раза при соответствующем уменьшении их толщины (Рис. 1). При дальнейшем нагреве форма данных дифракционных максимумов продолжает медленно изменяться в рамках отмеченной тенденции (Рис. 1). Зафиксированное изменение формы пиков свидетельствует о резком повышении степени совершенства кристаллической решетки твердого раствора. Обычно столь мощное изменение дифракционных максимумов фиксируется при протекании первичной рекристаллизации раннее деформированного металлического материала, и, соответствует, снижению плотности дислокаций и увеличению размеров ОКР. Следует отметить, что в данном случае процессу совершенствования ОЦК-решетки предшествовало выделение боридных и интерметаллидных фаз: появление их линий зафиксировано на дифрактограммах, полученных при температурах $600-625^{\circ} \mathrm{C}$ (Рис. 1). Можно предположить, что уход «не основных» атомов из твердого раствора с последующим их связыванием в соединения и дальнейшая коагуляция дисперсных фаз, освобождает границы между нанозернами. Избыточная поверхностная энергия границ зерен, имеющих нанораз- меры, служит мощным стимулом для быстрого укрупнения зерна, то есть некой «рекристаллизации» - по кинетике первичной, по механизму собирательной».

Выделение энергии в диапазонах температуры $523-543^{\circ} \mathrm{C}$ и $661-675^{\circ} \mathrm{C}$ на кривых калориметрического анализа (Рис. 2 a) указывает на наличие превращений. Рассчитанные значения удельной теплоты превращения составили соответственно 386 и 88 кДж/моль для кристаллизации и рекристаллизации соответственно. Эти значения хорошо согласуется с имеющимися в литературе данными для сплавов типа Finemet [18].

Дилатометрические исследования показали (Рис. 2 b), что в интервале от 500 до $560^{\circ} \mathrm{C}$ наблюдается провал кривой с нижним значением при $560^{\circ} \mathrm{C}$. Уменьшение толщины ленты связано с формированием более плотной кристаллической упаковки по сравнению с аморфной структурой [3]. Затем при температуре $640^{\circ} \mathrm{C}$ кривая снова стремится вниз. Изменение толщины ленты в ходе кристаллизации составила примерно $5 \%$.

Таким образом, с уменьшением скорости нагрева существенно понижается температура кристаллизации, а температура рекристаллизации снижается незначительно. Для всех скоростей нагрева в интервале темпера-
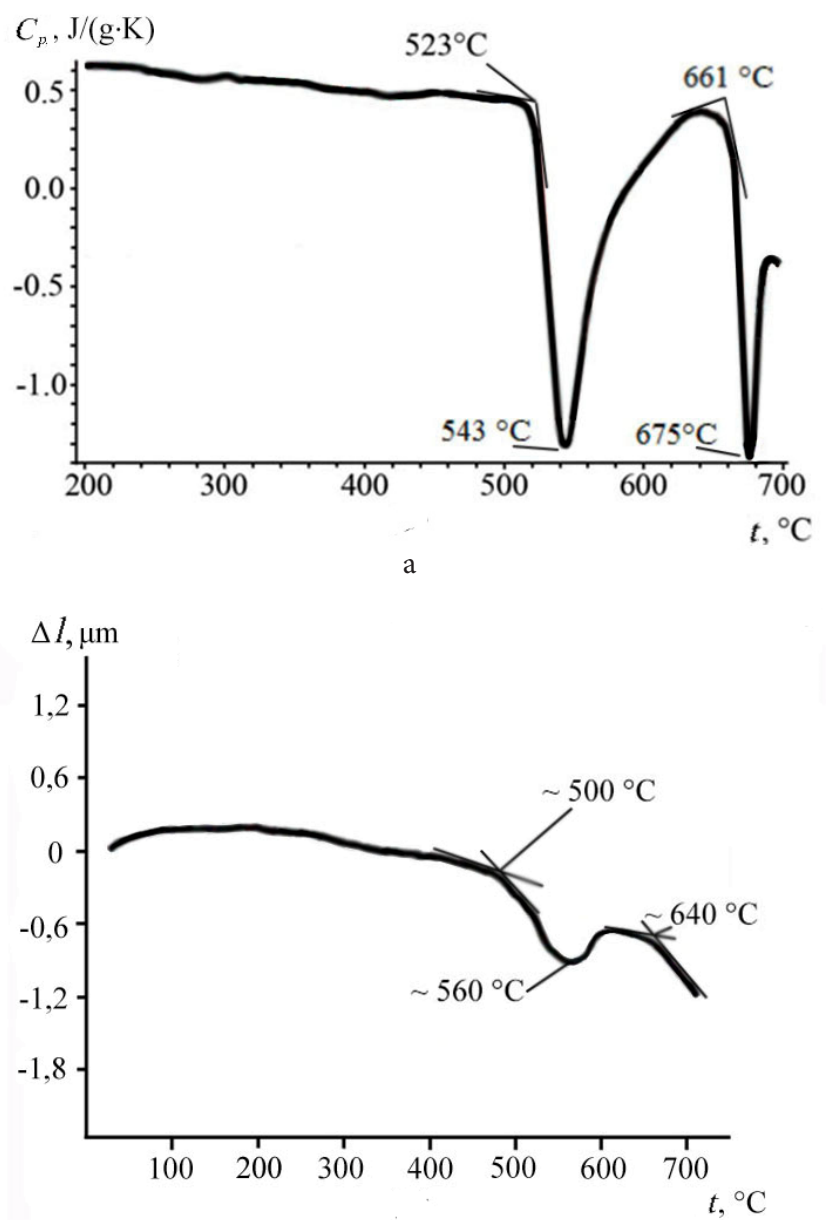

$\mathrm{b}$

Рис. 2. Изменение удельной теплоемкости $C_{p}$ (a) и толщины ленты $\Delta l$ (b) в зависимости от температуры сплаваFе ${ }_{72.5} \mathrm{Cu}_{1} \mathrm{Nb}_{2} \mathrm{Mo}_{1.5} \mathrm{Si}_{14} \mathrm{~B}_{9}$.

Fig. 2. $\mathrm{Fe}_{72.5} \mathrm{Cu}_{1} \mathrm{Nb}_{2} \mathrm{Mo}_{1.5} \mathrm{Si}_{14} \mathrm{~B}_{9}$ alloy specific thermal capacity $C_{p}$ (a) and ribbon thickness changes $\Delta l(\mathrm{~b})$, depending on the temperature. 
тур $530-570^{\circ} \mathrm{C}$ сплав находился в нанокристаллическом состоянии.

На основе сопоставления результатов рентгенографических и калориметрических исследований проанализирована возможность применения модели структурных единиц к описанию аморфного состояния.

Предполагается, что вследствие симметрии распределения электронной плотности, за счёт которой осуществляется межатомное взаимодействие в конденсированных состояниях, хаотичные расположения атомов (подобное реализующемуся в газах или ближний порядок в жидкостях) - невозможно. Более того, количество стабильных и метастабильных упорядоченных расположений атомов является строго ограниченным для поликристаллических твердых тел. Это означает, что сопряжение между кристаллическими решетками отдельных зёрен в виде высокоугловых границ должно быть упорядоченным на атомном уровне, то есть реализовываться в виде специальных границ [19]. Кристаллографическое описание структуры специальных границ строится либо в рамках модели решетки совпадающих узлов (РСУ), либо в рамках модели структурных элементов.

С точки зрения вышеизложенных представлений в конденсированных аморфных фазах не может существовать относительно хаотичного расположения атомов в виде ближнего порядка, при этом возможным является представление о структуре, состоящей из малых кристаллографически упорядоченных объемов (структурных элементов), в которых сопряжение между атомами происходит различным образом внутри и на границах. «Малость» структурного элемента означает, что число атомов внутри него сопоставимо с количеством атомов на его границах. Таким образом, «аморфное состояние» в данном случае представляется как совокупность очень малых структурных элементов - «ультрананокристаллических» (то есть имеющих размер меньше, чем «нано», несколько межатомных расстояний).

В контексте данной работы предполагалось, что все конденсированные состояния материала (аморфное, нанокристаллическое и рекристаллизованное) отличаются размерами областей когерентного рассеяния (ОКР).

По рассчитанным ОКР строилась модель предполагаемой структуры. Ячейка Вигнера-Зейтца (В-3) при- нималась как минимальная структурная единица этой модели. ОКР для различных структурных состояний представлялись в качестве областей, полностью заполненные ячейками одного типа (Рис. 3). Таким образом, ОКР соответствует определенному количеству ячеек В-3, объединенных в кластер (структурный элемент) с единой ориентацией кристаллической решетки. Данное представление транслировалось на аморфное и нанокристаллическое состояния.

С точки зрения моделей конденсированного состояния, полагающих стыковку зерен в поликристаллах только в виде специальных границ [20], предполагается, что во всех анализируемых состояниях области с кристаллической решеткой (кластеры, нанокристаллы или зерна) ограничены стабильными (малоподвижными) специальными границами двух типов: близких к границам РСУ $\Sigma 3$ и $\Sigma 11$ [21].

Нижняя оценка размеров $(L)$ областей когерентного рассеяния проводилась по уширению линии ОЦК-железа $\{110\}$ а и по гало для аморфного состояния. По уравнению Вульфа-Брегга для материала в кристаллических состояниях вычисляли межплоскостное расстояние $(d)$ по линии $\{110\}$. Для аморфного состояния по положению центра тяжести гало определялось среднее межатомное расстояние по первой координационной сфере.

Объем ячейки В-3 $V_{\text {cellx }}$, который соответствовал объему усеченного октаэдра через половину объема куба, и объем ОКР $V_{\text {CSR }}$, форма которой принималась за шар, вычисляли по формулам

$$
\begin{gathered}
V_{\text {cell } x}=\sqrt{2} d_{x}^{3}, \\
V_{\mathrm{CSR} x}=\pi L_{x}^{3} / 6,
\end{gathered}
$$

где $x$ - состояние материала, которое может быть $x \equiv a-$ аморфным, $x \equiv n-$ нанокристаллическим, $x \equiv r-$ рекристаллизованным. Для определения объема ОКР без учета последнего атомного слоя использовали соотношение

$$
V_{\mathrm{CRS} x}^{\prime}=\pi\left(L_{x}-\sqrt{2} \cdot d_{x}\right)^{3} / 6 .
$$

Объем последнего атомного слоя в ОКР

$$
V_{x}=V_{\mathrm{CSR} x}-V_{\mathrm{CSR} x}^{\prime},
$$

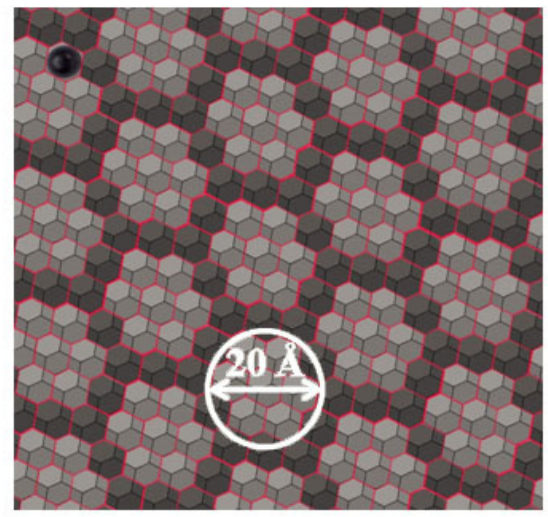

a

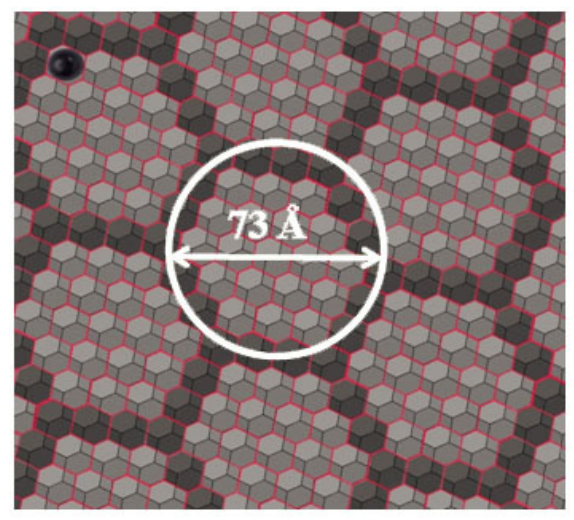

$\mathrm{b}$

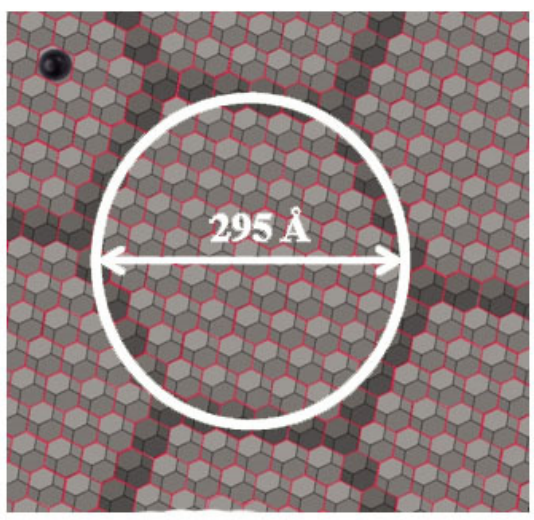

c

Рис. 3. Модель структурных единиц для аморфного (a), нанокристаллического (b) и рекристаллизованного (c) состояний.

Fig. 3. The structure unit model for amorphous (a), nanocrystalline (b) and recrystallized (c) state. 
и он соответствовал объему атомов, входящих в границу между кластерами.

По вычисленным объемам вычисляли относительное количество атомов в объеме ОКР, включая границы области,

$$
N_{x \Sigma}=V_{\operatorname{CSR} x} / V_{\text {cell } x},
$$

и на границе ОКР

$$
N_{x}=V_{x} / V_{\text {cell } x} .
$$

В качестве структурного параметра использовался отношение

$$
K_{x}=N_{x} / N_{x \Sigma}
$$

которое имеет смысл относительного количества атомов на границе ОКР. Величины рассчитанных параметров для различных состояний материала обобщены в Табл. 1.

В принятой модели удельная теплота превращения представляет энергию, выделяемую при переходе атомов из состояния с частично скомпенсированными связями, т. е. для атомов, находящихся на границе ОКР, в узел кристаллической решетки, т. е. внутрь ОКР. Эти соображения позволяют утверждать, что отношение удельной теплоты кристаллизации $Q_{c r}$ и рекристаллизации $Q_{\text {rec }}$ должно совпадать с отношением числа атомов, поменявших свое положение в результате структурных преобразований.

Отношение для удельной теплоты преобразования

$$
\frac{Q_{c r}}{Q_{\text {rec }}}=4.4,
$$

а отношение числа атомов, поменявших свое положение,

$$
\frac{K_{a}-K_{n}}{0.8 \cdot\left(K_{n}-K_{r}\right)}=3.8,
$$

где $\left(K_{a}-K_{n}\right)$ - относительное число атомов, перешедших с границы во внутренний объем ОКР при кристаллизации, а $0.8 \cdot\left(K_{n}-K_{r}\right)-$ при рекристаллизации, с учетом того, что переходили только металлические атомы.

Таким образом, с учетом достаточно общих допущений, принятых в расчете, можно считать, что результаты расчетов (9) и (10) для структурных преобразований при нагреве аморфного прекурсора нанокристаллического сплава $\mathrm{Fe}_{72.5} \mathrm{Cu}_{1} \mathrm{Nb}_{2} \mathrm{Mo}_{1.5} \mathrm{Si}_{14} \mathrm{~B}_{9}$ находятся в удовлетворительном согласии с моделью структурных единиц.

\section{4. Выводы}

Использование методов калориметрии, дилатометрии и терморентгеновского фазового анализа позволило определить удельные теплоты кристаллизации 386 кДж/моль и рекристаллизации 88 кДж/моль при нагреве аморфного прекурсора нанокристаллического сплава $\mathrm{Fe}_{72.5} \mathrm{Cu}_{1} \mathrm{Nb}_{2} \mathrm{Mo}_{1.5} \mathrm{Si}_{14} \mathrm{~B}_{9}$. Результаты сравнения удельных теплот превращений и размеров областей когерентного рассеяния показали возможность использования модели структурных единиц для описания аморфного состояния.

Благодарности/Acknowledgements. Авторы выражают признательность за содействие программе поддержки ведущих университетов РФ в иелях повышения их конкурентоспособности №211 Правительства РФ №02. А03.21.0006. Исследование выполнено при финансовой поддержке РФФИ в рамках научного проекта №19-08-00071./The work was financially supported by the RF Government, No. 211 (contract No. 02. A03.21.0006). The reported study was funded by RFBR according to the research project №19-08-00071.

\section{Литература/References}

1. P. Duwes, R. H. Willens, W. Klement. Jr. Nature. 187, 869 (1960). DOI: 10.1038/187869b0

2. V.A. Milyutin, I. V. Gervaseva, V. S. Gaviko, E. G. Volkova, E. C. Beaugnon. Phys. Met. Metallogr. 118 (5), 493 (2017). (In Russian) [В.А. Милютин, И.В. Гервасьева, Е. Beaugnon, В. С. Гавико, Е. Г. Волкова. ФММ. 118 (5), 493 (2017).] DOI: 10.7868/S0015323017050084

3. V.S. Tsepelev, Yu.N. Starodubtsev, V.A. Zelenin, V.A. Kataev, V. Ya, Belozerov, V. V. Konashkov. Phys. Met. Metallogr. $118 \quad$ (6) $584 \quad$ (2017). (In Russian) [B.C. Цепелев, Ю.Н. Стародубце в В.А. Зеленин, В.А. Катаев, В.Я. Белозеров, В.В. Конашков. ФММ. 118 (6), 584 (2017).] DOI: $10.1134 /$ S0031918X17060096

4. R. Goldstein, D. Lisovenko, A. Chentsov, S. Lavrentyev. Letters on Materials. 7 (4), 355 (2017). (In Russian) [Р.В. Гольдштейн, Д.С. Лисовенко, А.В. Ченцов, С. Ю. Лаврентьев. Письма о материалах. 7 (4), 355 (2017). DOI: 10.22226/2410-3535-2017-4-355-358

5. C. Suryanarayana, A. Inoue. Inter. Mater. Rev. 58 (3), 131

табл. 1. Параметры модели структурных единиц сплава $\mathrm{Fe}_{72.5} \mathrm{Cu}_{1} \mathrm{Nb}_{2} \mathrm{Mo}_{1.5} \mathrm{Si}_{14} \mathrm{~B}_{9}$.

Table 1. Structural unit model parameters of $\mathrm{Fe}_{72.5} \mathrm{Cu}_{1} \mathrm{Nb}_{2} \mathrm{Mo}_{1.5} \mathrm{Si}_{14} \mathrm{~B}_{9}$ alloy.

\begin{tabular}{|c|c|c|c|c|c|c|c|}
\hline $\begin{array}{c}\text { Состояние } \\
\text { сплава } \\
\text { Alloy state }\end{array}$ & $L_{x}, \AA$ & $V_{\text {cellx }} \AA^{3}$ & $V_{\text {CSR } x} \AA^{3}$ & $d_{x}, \AA$ & $N_{x \Sigma}$ & $N_{x}$ & $K_{x}$ \\
\hline$a$ & 20 & 4.30 & $3.43 \cdot 10^{3}$ & 2.049 & $8 \cdot 10^{2}$ & $3 \cdot 10^{2}$ & 0.38 \\
\hline$n$ & 73 & 4.17 & $2.03 \cdot 10^{5}$ & 2.03 & $5 \cdot 10^{4}$ & $5.5 \cdot 10^{4}$ & 0.11 \\
\hline$r$ & 295 & 4.21 & $1.33 \cdot 10^{7}$ & 2.034 & $3.15 \cdot 10^{6}$ & $7.3 \cdot 10^{4}$ & 0.02 \\
\hline
\end{tabular}


(2013). DOI: 10.1179/1743280412Y.0000000007

6. Yu. Starodubtsev, V. Belozerov. Komponenty i tekhnologii. (4), 144 (2007). (In Russian) [Ю. Стародубцев, В. Белозеров. Компоненты и технологии. (4) 144 (2007).]

7. Y. Yoshizawa, S. Oguma, K. Yamauchi. J. Appl. Phys. 64 (10), 6044 (1988). DOI: 10.1063/1.342149

8. Y Yoshizawa, K. Yamauchi. Mater. Trans. 31 (4), 307 (1990). DOI: 10.2320/matertrans1989.31.307

9. G. Herzer. In: Handbook of magnetic materials (K. H. J. Buschow). Hanau, Elsevier. (1997). 3 (10) P. 415-462. DOI: 10.1016/S1567-2719(97)10007-5

10. Y. Q. Cheng, E. Ma. Progr. Mater. Sci. 56 (4), 379 (2011). DOI: $10.1016 /$ j.pmatsci.2010.12.002

11. L. Son, R. Ryltcev, V. Sidorov, D. Sordelet. Mater. Sci. Eng. 449 - 451, 582 (2007), DOI: 10.1016/j.msea.2006.02.342

12. D. V.Louzguine, V. I.Pol'kin. Izv.vuzov. Tsvet.metallurgiya. (6), 43 (2015). (In Russian) [Д. В. Лузгин, В. И. Полькин. Изв. вузов. Цвет. металлургия. (6), 43 (2015).] DOI: 10.17073/0021-3438-2015-6-43-52

13. D. B. Miracle, D. V. Louzguine-Luzgin, L. V. LouzguinaLuzgina, A. Inoue. Inter. Mater. Rev. 55 (4), 219 (2010). DOI: $10.1179 / 095066010 X 12646898728200$

14. V. A Polukhin, D. Kurbanova, N. A. Vatolin. Melts. 5, 337 (2017). (In Russian) [В. А Полухин, Э.Д. Курбанова, Н. А. Ватолин. Расплавы. (5), 337 (2017).]

15. V.S. Kraposhin. A. A. Talis. Melts. (2), 85 (2016). (In Russian) [В. С. Крапошин, А. А. Талис. Расплавы. 2, 85 (2016).]
16. Yu.N. Starodubtsev, V.Ya. Belozerov. Magnitnye svoistva amorphnykh i nanokristallycheskikh splavov. Ekaterinburg, Izdatelstvo Uralskogo Universiteta (2002) 366 p. (In Russian) [Ю. Н. Стародубцев, В. Я. Белозеров Магнитные свойства аморфных и нанокристаллических сплавов. Екатеринбург, Изд-во Урал. ун-та. (2002) 366 c.]

17. A.K. Shtolts, A.I. Medvedev, L.V. Kurbatov. Rentgenovskii analiz mikronapryazhenii i razmera oblastei kogerentnogo rasseyaniya $\mathrm{v}$ polikritallicheskikh materialakh. Ekaterinburg, UGTU-UPI (2005) 23 p. (In Russian) [А. К Штольц, А. И. Медведев, Л.В.Курбатов. Рентгеновский анализ микронапряжений и размера областей когерентного рассеяния в поликристаллических материалах. Екатеринбург, УГТУ-УПИ. (2005) 23 c.]

18. C. F. Conde, A. Conde. NanoStuctured Mat. 6 (1-4), 457 (1995). DOI: 10.1016/0965-9773(95)00095-X

19. O.A. Kaibyshev, R.Z. M. Valiyev. Granitsy zeren i svoistva metallov. Moskva, Metallyrgiya (1987) 214 p. (In Russian) [О.А. Кайбышев, Р.3. М. Валиев. Границы зерен и свойства металлов. Москва, Металлургия. (1987) 214 c.]

20. G. M. Rusakov, M.L. Lobanov, A.A. Redikul'tsev, A.S. Belyaevskikh. The Phys. of Met. and Metallogr. 115 (8), 775 (2014). DOI: 10.1134/S0031918X14080134

21. M. L. Lobanov, S. V. Danilov, V.I. Pastukhov, S. A. Averin, Y.Y. Khrunyk, A. A. Popov. Mat. and Design. 109, 251 (2016). DOI: 10.1016/j.matdes.2016.06.103 